Research article

\title{
The use of CAM by women suffering from nausea and vomiting during pregnancy \\ Taras Hollyer ${ }^{1}$, Heather Boon ${ }^{2}$, Alexia Georgousis ${ }^{1}$, Michael Smith ${ }^{1}$ and Adrienne Einarson*3
}

Address: ${ }^{1}$ Canadian College of Naturopathic Medicine, Toronto, Canada, ${ }^{2}$ Faculty of Pharmacy, University of Toronto, Canada and ${ }^{3}$ The Motherisk Program, The Hospital for Sick Children, Toronto, Canada

E-mail: Taras Hollyer - thollyer@ccnm.edu; Heather Boon - heather.boon@utoronto.ca; Alexia Georgousis - ageorgousis@ccnm.edu; Michael Smith - michael_j_smith-@ hc-sc.gc.ca; Adrienne Einarson* - einarson@ sickkids.on.ca

${ }^{*}$ Corresponding author

Published: 17 May 2002

BMC Complementary and Alternative Medicine 2002, 2:5

This article is available from: http://www.biomedcentral.com//472-6882/2/5

(C) 2002 Hollyer et al; licensee BioMed Central Ltd. Verbatim copying and redistribution of this article are permitted in any medium for any purpose, provided this notice is preserved along with the article's original URL.
Received: 22 March 2002 Accepted: 17 May 2002

\begin{abstract}
Background: Nausea and vomiting during pregnancy (NVP) affects two-thirds of pregnant women to varying degrees and over the years many modalities have been used to try to alleviate this often debilitating condition. There is a paucity of information in the literature about the use or efficacy of complementary and alternative medicine (CAM) for the treatment of this condition that affects so many women. Our primary objective was to examine the prevalence of CAM usage by women suffering from NVP. Our secondary objective was to ascertain if women had any supervision in the use of these treatments.
\end{abstract}

Methods: Women who called The Motherisk NVP helpline, were asked after the counseling session to complete a questionnaire, which included demographic data as well as information about their CAM use.

Results: Seventy women completed the questionnaire. 61\% reported using CAM therapies, of which the three most popular were: ginger, vitamin B6 and acupressure. $21 \%$ of those who reported using CAM, had consulted CAM practitioners, $8 \%$ their physicians or pharmacists and $71 \%$ discussed the usage with family, friends and other allied health professionals. Women who did not use CAM stated they would probably use these modalities if there was more information about the safety in pregnancy.

Conclusion: Pregnant women with NVP are mirroring the trend in the general population of the use of CAM. They are also using CAM therapies with little supervision from practitioners experienced in the use of these modalities.

\section{Introduction}

Nausea and vomiting during pregnancy (NVP) affects up to $80 \%$ of all pregnant women, and has a significant impact on the quality of life of those who experience it $[1,2]$.
The effects can range from mild nausea to more severe forms such as hyperemesis gravidarum, which is characterized by an intractable nausea and vomiting so severe that it can lead to hospitalization. Although only 0.3 to $3 \%$ of 
pregnant women are diagnosed with hyperemesis gravidarum [3], less severe forms of NVP exert a significant impact on the quality of life of those affected [1]. In one study, close to $50 \%$ of employed women reported reduced work efficiency due to NVP, with as many as $25-66 \%$ of women actually requiring time off work. Furthermore, almost $50 \%$ of women reported that their NVP negatively affected their relationship with their partner as well as having an adverse effect on their partner's day-to-day life [4].

There are a number of effective options available for the alleviation of NVP, varying from non-pharmacological strategies such as diet and lifestyle changes to pharmacological treatments such as Diclectin ${ }^{\circledR}$ (doxylamine/pyridoxine) [5], antihistamine H1 blockers [6], phenothiazines [7], as well as pyroxidine (vitamin B6) alone $[3,8]$. The thalidomide tragedy of the 1960 's as well as the Bendectin ${ }^{\circledast}$ unfounded scare of the mid 1980's $[9,10]$ has caused women with NVP to look on drug-based strategies with great caution due to concerns over the perceived teratogenicity of these drugs $[4,11]$, even when data exist documenting safety $[5,9,10]$. Accordingly, non-pharmacological strategies to alleviate NVP may be popular choices amongst pregnant women. In addition to dietary and lifestyle changes, the use of (CAM) to alleviate NVP may be an attractive option for many women. The perceived "natural" status of herbal products in particular and CAM in general lead many to draw the conclusion that CAM therapies are not associated with adverse effects.

The use of CAM has increased rapidly in the last decade $[12,13]$. Estimates of the prevalence of CAM use in the United States were as high as $42 \%$ in 1997, with CAM use particularly popular among women of reproductive age $[12,13]$. In addition, almost half of women surveyed reported using CAM (48.2\%) [12]. Consequently, the possibility that pregnant women are using CAM to alleviate complaints such as NVP is quite possible, although the exact percentage remains unknown. The use of CAM therapies among pregnant women is an important but little studied issue. One study assessing the CAM prescribing patterns of Nurse-Midwives in North Carolina revealed that almost half of nurse-midwives surveyed recommended CAM therapies to more than $10 \%$ of their patients[14]. Another study of women attending antepartum visits revealed that almost $10 \%$ of these women reported using herbal supplements during their pregnancy, with $7.5 \%$ of these women using these preparations on a weekly basis [15]. Furthermore, $13.5 \%$ of these women reported using other non-herbal CAM therapies. There are a handful of studies suggesting effective relief of NVP by CAM therapies such as ginger $[3,16]$, manual acupuncture $[17,18]$, acupressure [3] and vitamin B6 [3,8]. Nevertheless, there is little research on the efficacy and safety of the full range of CAM modalities used by women to alleviate NVP. Furthermore, there is little information about the types of CAM treatments that are being used by women experiencing NVP, as well as how they obtain information about potential CAM therapies Finally, the degree of supervision of CAM use in this population is not well defined.

This pilot study was undertaken to investigate the prevalence, supervision and types of CAM treatments used for NVP by women using the NVP counseling line at the Motherisk Program located at the Hospital for Sick Children in Toronto, Ontario.

\section{Patients and methods}

Women receiving counseling by the Motherisk Program NVP line, who call us from across North America, were asked whether or not they wished to complete a phone survey regarding their use or non-use of CAM to alleviate their NVP. The questionnaire was administered to the survey participants either directly following the counseling session or at a later time mutually agreed upon by the participant and the interviewer.

Demographic data were collected for all of the survey respondents including the number of previous children, previous experience with NVP, pregnancy-related medication as well as any adverse experiences related to pregnancy-related medication. In addition, all respondents were asked to describe the severity of their NVP on a scale of 0 10 , with 10 being the most severe, as well as whether or not they had previously used CAM. Survey respondents who reported non-use of CAM to alleviate NVP were asked to agree or disagree with a series of possible reasons why they did not use CAM to alleviate their NVP. The level of agreement was measured by a 5-point Likert Scale, where 1 = strongly disagree, 2 = disagree somewhat, $3=$ undecided, $4=$ somewhat agree and $5=$ strongly agree. Respondents who reported using CAM to alleviate their NVP were asked which CAM therapies they had used. They were also asked how they found out about CAM therapies, and whether or not their CAM use was supervised by a licensed health care practitioner who practiced CAM either as part of their practice or in whole. Users of CAM were also asked 9 possible reasons why they chose to use CAM to alleviate their NVP, using the same Likert Scale used for non-CAM users.

The demographic data, reported severity of NVP, and previous CAM use were compared between users and non-users of CAM. The level of agreement with statements regarding CAM use or non-use was reported as a mean Likert Scale value plus standard deviation. Simple numerical analysis was used to report the types of CAM interventions used as well as the numbers and types of 
practitioners consulted and source used to access CAM information.

\section{Results}

A total of seventy out of 110 women consented to be interviewed and completed the questionnaire. 10 women refused to participate and 30 were lost to follow up. The demographics of the women lost to follow up did not differ significantly from the respondents. Demographic characteristics of the questionnaire respondents are summarized in Table 1. Almost half of the respondents were between the ages of 30-34. In addition, the majority were married (or living with a partner), Caucasian, had completed a college, university or post-graduate degree and reported a total household income of $\$ 41,000$ (CDN) / year or greater. Almost half were employed full-time and one-third identified themselves as homemakers. Most survey respondents indicated that they had one child or less at time of interview and two-thirds reported having experienced nausea and vomiting in a previous pregnancy.

Half of the respondents reported using pharmaceutical drugs during their pregnancy, with Diclectin ${ }^{\circledR}$ being the most commonly used medication (used by two-thirds of those who indicated that they had taken medication). More than half of all Diclectin ${ }^{\circledR}$ users reported an adverse effect from the drug, namely drowsiness, with three women also reporting irritability and dry mouth. Most of the respondents reported that their family physician or obstetrician was their primary obstetric caregiver at the time of the interview.

Almost two-thirds (61.2\%) of the survey respondents reported using CAM to alleviate NVP. The three most common types of CAM used are summarized in Table 2 and were: ginger teas or tablets, accupressure / seabands, and Vitamin B6). The most common information sources for respondents about the use of CAM for NVP are also summarized in Table 2 and were: family and friends, women's health centres, or pregnancy counseling lines, CAM practitioners followed by their doctor or pharmacist. The most commonly consulted CAM practitioners were acupuncturists, chiropractors, homeopaths and naturopaths. Only $21.6 \%$ of respondents consulted with a CAM practitioner when using CAM to alleviate NVP. Furthermore, $20.7 \%$ of CAM users reported mild adverse reactions associated with using CAM to alleviate their NVP. The most commonly reported adverse experiences were the intolerability of the strong flavour of ginger and wrist irritation among respondents who used acupressure wrist bands.

Survey respondents were asked why they chose to use CAM to alleviate their NVP (table 3) and were also asked why they did not use CAM (table 4). The most common reason given for using CAM was: because this was not re-
Table I: Demographic Characteristics of Survey Respondents

No. Percent Total No. of Respondents

Age

$\begin{array}{rrrr}20-24 & 3 & \\ 25-29 & 16 & 22.9 \\ 30-34 & 34 & 48.6 \\ 35-39 & 16 & 22.9 \\ 40-45 & 1 & 1.4\end{array}$

Declared Ethnicity

$\begin{array}{rrr}\text { Caucasian } & 60 & 87.0 \\ \text { Latin American } & 3 & 4.3 \\ \text { Black } & 3 & 4.3 \\ \text { Other } & 3 & 4.3\end{array}$

Marital/Civil Status

Married/ Living with $\mathrm{P}$ Separated / Divorced I 1.4

Highest Level of Education $\begin{array}{lll}\text { public school } \quad 3 & 4.7\end{array}$ high school $\quad 10 \quad 15.6$ college / university $43 \quad 67.2$ $\begin{array}{lll}\text { post-graduate training } \quad 8 & 12.5\end{array}$

Previous Number of Children

$\begin{array}{rrr}0 & 21 & 30.9 \\ 1 & 28 & 41.2 \\ 2 & 13 & 19.1 \\ 3 & 6 & 8.8\end{array}$

Total Household Income

$<\$ 10,000 /$ yr. $2 \quad 3.3$

$\$ 10,000-<\$ 20,000 \quad 3 \quad 5.0$

$\$ 20,000-<\$ 30,000 \quad 6 \quad 10.0$

$\$ 30,000-<\$ 40,000 \quad 6 \quad 10.0$

$\$ 40,000-<\$ 50,000 \quad 8 \quad 13.3$

Type of Employment

greater than $\$ 50,000 \quad 35 \quad 58.3$

Previous NVP Experience

$\begin{array}{lll}\text { unemployed } & \text { I } & 2.7\end{array}$ part-time $\quad 5 \quad 13.9$ full time $\quad 16 \quad 44.4$ $\begin{array}{lll}\text { student } \quad \mathrm{I} & 2.7\end{array}$ 36.1

Obstetric Care

Yes $\quad 35 \quad 67.3$


Table 2: Common CAM Treatments, Practitoners and Information Sources Used for NVP

The Most Common CAM treatments $\%$
used for NVP *

I. ginger teas or tablets $\quad 50.7$

2. accupressure/seabands $\quad 45.8$

3. Vitamin B6 29.2

The Most Common Sources Used for Obtaining Information About CAM

I. Friends/family

2. Allied health professionals

3. CAM practitioners

4. Doctor / Pharmacist

The Most Commonly Consulted CAM Practitioners

I. acupuncturists

63.6

2. chiropractors

18.2

3. naturopaths

10

4. homeopaths

9.1

*Some women used more than one

Table 3: Common Reasons Respondents Chose CAM to Alleviate NVP.*

\begin{tabular}{lc}
\multicolumn{1}{c}{ Most Common Reasons } & Mean+SD \\
\hline $\begin{array}{l}\text { I do not like to use drugs unless it is neces- } \\
\text { sary }\end{array}$ & $4.52 \pm .78$ \\
I did not want to use drugs for fear of harm- & $4.20 \pm 1.2$ \\
ing my baby & $4.12 \pm 1.0$ \\
I wanted to be more in control of my health \\
care decisions
\end{tabular}

\section{Least Common Reasons}

I was prescribed medicines for my NVP which gave me side effects

\footnotetext{
* $\mathrm{I}$ = strongly disagree, 2 = somewhat disagree, $3=$ undecided, $4=$ somewhat agree, 5 = strongly agree
}

Table 4: Common Reasons Respondents did not Choose CAM to Alleviate NVP.*

\begin{tabular}{lc}
\hline \multicolumn{1}{c}{ Reasons Most Agreed Upon } & Mean+SD \\
\hline & \\
I would feel more comfortable in using CAM & $4.0 \pm .98$ \\
if I had access to someone who is knowledge- & \\
able about its use & $3.97 \pm \mathrm{I} . \mathrm{I}$ \\
I would like more information about CAM & \\
before I use it &
\end{tabular}

\section{Reasons Least Agreed Upon}

$\begin{array}{lc}\text { I have had some bad experiences with CAM } & 1.7 \pm .59 \\ \text { in the past } & \\ \text { I have had some bad experiences with CAM } & 1.7 \pm .84 \\ \text { practitioners in the past } & \\ \text { CAM use is against my religion } & 1.5 \pm .82\end{array}$

* I = strongly disagree, 2 = somewhat disagree, 3 = undecided, $4=$ somewhat agree, $5=$ strongly agree

Table 5: Possible predictors of CAM use in Women Suffering From NVP $(\mathbf{n}=\mathbf{5 8})$

\begin{tabular}{ccc}
\hline Predictor & Chi square & Two-sided p-value \\
\hline & & \\
Level of Education & 0.061 & .804 \\
Income & 0.055 & .815 \\
Previous CAM use & 1.662 & .197 \\
\hline & & \\
Severity of NVP & 6.801 & 0.009 \\
\hline
\end{tabular}

"Severity" here is defined as experiencing nausea and vomiting greater than three times / day

ally a "drug" and it was probably safer to use in pregnancy than a pharmaceutical product. The most common reason for not using CAM was: there was not enough information about the use of these products.

The level of education, income, severity of NVP, and previous CAM use were assessed as possible predictors of CAM use in survey respondents. Out of these four factors assessed, only NVP severity was associated with CAM usage to alleviate NVP: Table 5

\section{Discussion}

This study was undertaken to investigate the prevalence, types of CAM treatments used and supervision if any, of 
the treatment of nausea and vomiting of pregnancy by women using the NVP counseling line at the Motherisk Program at the Hospital for Sick Children in Toronto, Ontario, Canada. Because the use of CAM has become more prevalent in the general population in recent years, coupled with the fact that $70 \%$ of all pregnant women suffer from NVP, one might be able to extrapolate these results to the general population of women who suffer from NVP, but did not call the NVP helpline. It is a fact that women who call the NVP helpline do have a higher SES status and it is known that SES status has an impact on the use CAM.(19) However, there was no correlation between the use of CAM and higher SES in our study, the only factor that predicted the use of CAM was the severity of NVP. This finding may appear to be suprising, however it was not to us at the Motherisk NVP Helpline, because over the years, many women have told us that NVP can be so debilitating that they will try just about anything to alleviate their symptoms.

Our results showed that CAM was used by almost twothirds of our surveyed population of women experiencing NVP. Even the women who did not use CAM felt they would have if there was more information on the safety during pregnancy. We also found that CAM use in this population is largely unsupervised, with most women getting information from their family and friends and buying the products directly from herbal stores. Women who used CAM reported that it made them feel more in control of their health care decisions and that they perceived it would be safer than pharmaceutical products.

The population at large has probably been exposed to the use of CAM through media, such as television and magazines as well as the internet, which is present in almost half of the homes in the country and may feel that because of this they are knowledgable about this form of medicine. Many people today feel that they would like to be more in control of their own health care and perceive that CAM allows this, as neither a prescription nor physician visit is required for the use of these treatments.

Natural is often perceived as "safe" which is not necessarily always the case. This perception can be especially true with pregnant women, who wish to protect their fetuses from "harmful things" such as pharmaceutical products. This is born out by the fact that many women call our general Motherisk Program information line asking about the safety of other CAM use during pregnancy, as they feel this would be a safer option for their baby. The number of calls about the use of CAM in general during pregnancy has increased dramatically over the past few years reflecting the population's interest in this form of treatment. Unfortunately, we have to inform the callers that there is scant research on the use and safety of CAM during preg- nancy, whereas there are quite a substantial number of studies in the current literature regarding the use and safety of pharmaceutical products during pregnancy.

The limitation of this study is primarily the small sample size, as seventy women are a low number for a survey of this kind. It is also not a population based study as women who call our helpline do differ in some ways from the general population.

In summary, a significant amount of women are using CAM in pregnancy for the treatment of NVP, despite the lack of safety or efficacy data and often without any supervision from a knowledgable practitioner. Further research in this field may allow pregnant women more options in treating this very common conditon of pregnancy.

\section{Competing interests}

None declared.

\section{Authors' contributions}

Author 1 conceived the study and participated in writing the paper

Author 2 participated in writing the paper

Author 3 participated in study design and carried out the study

Author 4 participated in study design

Author 5 participated in study design, writing of paper and overall coordination.

\section{Acknowledgements}

The Motherisk Nausea and Vomiting Helpline is supported by Duchesnay Inc. Laval, Quebec, Canada

\section{References}

I. O'Brien B, Naber S: Nausea and vomiting during pregnancy: effects on the quality of women's lives. Birth 1992, I9(3): 138-43

2. Gadsby R, Barnie-Adshead AM, Jagger C: A prospective study of nausea and vomiting during pregnancy. Br J Gen Pract 1993, 43(37I):245-8

3. Broussard CN, Richter JE: Nausea and vomiting of pregnancy. Gastroenterol Clin North Am 1998, 27(I): 123-51

4. Koren G, BR ed: Nausea and Vomiting of Pregnancy: state of the art 2000. Vol. I. Motherisk: Toronto. 2000, 219

5. McKeigue PM, et al: Bendectin and birth defects: I. A metaanalysis of the epidemiologic studies. Teratology I994, 50(I):2737

6. Seto A, Einarson T, Koren G: Pregnancy outcome following first trimester exposure to antihistamines: meta-analysis. Am J Perinatol 1997, I 4(3): I 19-24

7. Mazzotta $P$, Magee LA: A risk-benefit assessment of pharmacological and nonpharmacological treatments for nausea and vomiting of pregnancy. Drugs 2000, 59(4):78I-800

8. Sahakian V, et al: Vitamin B6 is effective therapy for nausea and vomiting of pregnancy: a randomized, double-blind placebocontrolled study. Obstet Gynecol 1991, 78(I):33-6

9. Korcok M: The Bendectin debate. Can Med Assoc J 1980, I 23(9):922-8 
10. Ornstein M, Einarson A, Koren G: Bendectin/diclectin for morning sickness: a Canadian follow-up of an American tragedy. Reprod Toxicol 1995, 9(1): I-6

II. Mazzotta $P$, et al: The perception of teratogenic risk by women with nausea and vomiting of pregnancy. Reprod Toxicol 1999, 13(4):313-9

12. Eisenberg DM, et al: Trends in alternative medicine use in the United States, 1990-1997: results of a follow-up national survey. Jama 1998, 280(1 8):1569-75

13. Eisenberg DM, et al: Unconventional medicine in the United States. Prevalence, costs, and patterns of use. N Engl J Med 1993, 328(4):246-52

14. Allaire $A D$, Moos MK, Wells SR: Complementary and alternative medicine in pregnancy: a survey of North Carolina certified nurse-midwives. Obstet Gynecol 2000, 95(I):19-23

15. Gibson PS, Powrie R, Star J: Herbal and alternative medicine use during pregnancy: a cross-sectional survey. Obstet Gynecol 200I, 97(4 SuppI I):S44-S45

16. Vutyavanich T, Kraisarin T, Ruangsri R: Ginger for nausea and vomiting in pregnancy: randomized, double-masked, placebo-controlled trial. Obstet Gynecol 200I, 97(4):577-82

17. Carlsson CP, et al: Manual acupuncture reduces hyperemesis gravidarum: a placebo-controlled, randomized, single-blind, crossover study. J Pain Symptom Manage 2000, 20(4):273-9

18. Knight $B$, et al: Effect of acupuncture on nausea of pregnancy: a randomized, controlled trial. Obstet Gynecol 200I, 97(2): I84-8

19. Wolsko PM, Eisenberg DM, Davis R, Ettner S, Phillips R: Insurance coverage, medical conditions and visits to alternative medicine providers: results of a national survey Arc Intern Med 2002, 162:28I-287

\section{Pre-publication history}

The pre-publication history for this paper can be accessed here:

http://www.biomedcentral.com/1472-6882/2/5/prepub

\section{Publish with BioMed Central and every scientist can read your work free of charge}

"BioMedcentral will be the most significant development for disseminating the results of biomedical research in our lifetime." Paul Nurse, Director-General, Imperial Cancer Research Fund

Publish with BMC and your research papers will be:

- available free of charge to the entire biomedical community

- peer reviewed and published immediately upon acceptance

- cited in PubMed and archived on PubMed Central

- yours - you keep the copyright 